\title{
When Club Culture Goes Online: \\ THE CASE OF BOILER ROOM ${ }^{1}$ \\ $\because$ Transposition $\longrightarrow$ \\ Guillaume Heuguet \\ Université Paris SorbonNe (France) \\ Translation by LUis-ManUel Garcia \\ UNIVERSITY OF BIRMINGHAM (UNITED KINGDOM)
}

\begin{abstract}
Contemporary media technologies are often perceived as providing an opportunity to widen the audiences of cultural events. Online video broadcast ("streaming") formats seem to be especially promising for popular music events. This article analyzes the encounter between these club/rave cultures and streaming technology through a dual event-both on-site and mediatized—run by a [relatively] new organization, Boiler Room. Video streaming seems to offer the promise of alleviating many obstacles to participation historically associated with underground culture, but in doing so it also threatens to undermine the specialist exclusivity that contributes to the community's own sense of authenticity. This article is interested in how event organizers appropriate such technologies, adjusting them to club culture in order to develop online an original variant of the DJ experience. I aim to show how decisions regarding stage design, videography, and website development all contribute to building the social significance and specificity of an episode in club culture.
\end{abstract}

KEYWORDS: television; internet; spectatorship; authenticity; web design; semiotics

Guillaume Heuguet is a PhD candidate in Communication and Information Sciences at GRIPICCelsa (Université Paris Sorbonne). His work focuses on digital media, music culture and journalism. $\mathrm{He}$ is chief editor of the French series in music criticism, Audimat (http://revue-audimat.fr/), and collaborates with the publisher, La Rue Musicale (Philarmonie de Paris).

Dancecult: Journal of Electronic Dance Music Culture 8(1): 73-87

ISSN 1947-5403 @2016 Dancecult http://dj.dancecult.net http://dx.doi.org/10.12801/1947-5403.2016.08.01.04 
TRANSLATOR'S INTRODUCTION: In this article, Heuguet provides a deep semiotic reading of Boiler Room's online remediation of underground dance music events. In particular, he examines closely a handful of webpages, video streaming frameworks, and social media interfaces related to a specific Boiler Room event in 2012, drawing upon a nuanced notion of mediation (Hennion 2015) and of the "media event" as a genre of cultural happening designed to be mediatized (Dayan and Katz 1994). The analysis has a range of foci, including event design, videographic staging, website design, and social media integration. In this manner, Heuguet tracks how Boiler Room's organizers navigate a careful path between the tensions that arise between the two experiential modes they strive to connect: "underground" exclusivity and subcultural specialization versus mass audiences and open accessibility; televisual staging versus realist-candid static camera shots; financial dependence on brand sponsorship (i.e., indirect advertising revenue) versus anti-corporate counterculture; face-to-face corporeal intimacy versus online social media. Ultimately, this article returns repeatedly to issues of authenticity and artifice, demonstrating how Boiler Room has developed an evidently successful compromise between the two. Guillaume Heuguet's article first appeared in French in 2015 as "Quand la culture de la discothèque est mise en ligne". Culture et Musées 24: 107-24.

After television, which may have seemed like an outlet for state cultural policy concerning live entertainment (Bouquillon 1992), contemporary technologies are often perceived as an opportunity to widen the audiences of cultural events. Online video broadcast ("streaming") formats thus represent a particular challenge for events associated with "legitimate" culture seeking to reach a broader audience. At the same time, these formats seem already custombuilt for cultures considered "popular". By virtue of representations of the internet over the past few years that have characterized it as a "social" and democratic medium (Candel 2014) as well as the connection between popular musics and technologies of mass broadcast like the record (Maisonneuve 2009) or television (Blanchard 1987), the broadcast of popular music concerts has found its logical extension online, with new opportunities for musicians to gain visibility and for experiences adapted to remote spectatorship.

This logic, which consigns these musics to mass circulation across digital media, requires nuance in light of two other phenomena. One the one hand, there is the specialization within these musical worlds, which recreates aesthetic hierarchies between and even within genres, which in turn serve as vectors of social distinction (Glevarec and Pinet 2009: 73-5). On the other hand, there is a developing sense of historicity in relation to popular musics as well as a rise in activities that constitute them as heritage, such as the multiplication of national exhibitions dedicated to rock or electronic musics (Le Guern 2013). These musics, insofar as they give rise to specialist cultures appreciated by amateur-experts, take on values by which technological mediations can be judged to be transformative (Hennion 2007: 312; Hennion 2015), whether positively or negatively so. Thus, video and the internet are not simple broadcast outlets, but rather mediations that change the form and modalities of musical appropriation. 
One particularly interesting case is the "DJ-mix,"2 the musical practice of disc-jockeys (DJs) that consists of playing records in venues dedicated to festive outings-clubs and discotheques-in order to make a crowd dance while also demonstrating technical and aesthetic competence. As this musical practice becomes a full-fledged object of consumption in the form of recordings published on disc or online (e.g., CD-mixes, podcasts), fans concerned with the aesthetics of the disc-as-object construct hypotheses about the intentions of producers and adequate modes of listening: a bootleg recording of a public DJ-mix bought on the black market does not accrue the same meanings as a mix recorded specifically for a record label. These evaluative parameters for media objects and broadcast settings are connected to a "culture of the discotheque" - club culture-connected in turn to the practices of DJs and their aesthetic use of discs-DJ culture-such as it has been analyzed and designated by scholars for more than a decade (Fikentscher 2000; Lawrence 2003; Shapiro 2007). Studies of these practices are marked by ambivalent stances, desiring to preserve a communal identity while also producing euphoric representations of openness and sharing.

This article seeks to analyze the encounter between these cultural forms and technology through a dual event-both on-site and mediatized-run by a new organization called Boiler Room. I will observe the different editorial frameworks that stage a festive event that took place on 25 January 2012, in a disused public pool in Berlin, Stattbad Wedding, featuring the DJs Dixon, Move D, Jus-Ed and the duo Midnight Operator. I aim to show how decisions regarding stage design, videography, and website development all contribute to building the social significance and specificity of an episode in club culture.

\section{DANCING TO RECORDS}

According to Bill Brewster and Frank Broughton, the origins of the discothèque are to be found somewhere between Jimmy Saville in Leeds, who was allegedly the first to make people dance to records, ${ }^{3}$ and the many nightlife establishments that opened in Paris after the war (Brewster and Broughton 2007: 52-62). In February 1965, the New York Times sought to describe a burgeoning phenomenon in the US: "The common denominator of the discothèque is darkness, a small dance floor and the beat" (Lawrence 2003: 14). Since that era, when it was described a trend with no tomorrow, the discothèque has turned into an institution: these spaces would henceforth connote rituals of youthful socialization, seduction and dancing. They have given rise to a cultural history that endeavors to describe the contours of a constantly evolving club culture. After having emerged at a time when disc jockeys were replacing (conventional) musicians, this culture eventually spilled out of nightclubs in the 1980s, when English youth spurned the exclusive and expensive nightlife venues in London's city center in favor of dancing in open fields in the suburbs. In addition to the diversity of venues, atmospheres and crowds, historical accounts of these parties all emphasize the political and at times elitist dimensions of these spaces; they characterize these events as conducive to experimentation with identity and social relations. Seeking to remain faithful to the particularity of events where DJs, much like jazz musicians (Becker 
1985), navigate between artistic originality and the functional dimensions of dance music, Morgan Jouvenet gleans from her interviews a shared pursuit of a form of trance, a "transport" that also functions as a "blast off [décollement] from the trivial-social" (2001: 22). This experience of the nightclub as a site of achieved utopia - as a space "enchanted" by a sense of equality-informed accounts of those New York discothèques frequented by gay Latinos and African-Americans (Lawrence 2003) as well as those of Paris and London, not to mention the raves and free parties that gained prominence during the 1990s. This musical abandon goes together with a bracketing of social roles and aims to consolidate the effects of communal commixture. The extent and quality of the audience appears in the majority of accounts as the primary determinants of one's experiences. On every occasion, participants were obliged to overcome qualifying hurdles in order to access the event. This is the case for clubs and their "door policy," but also for raves and free parties, since the illicit nature of these festivities also entailed logistical obstacles that served as a veritable initiatory quest. What happens, then, when the mediatization of these parties online seems to alleviate these logistical obstacles?

This article is interested in how an organizer of musical events appropriates these technologies, adjusting them to club culture in order to develop online an original variant of the DJ-mix experience. The Boiler Room project was born in London in 2011, launched by Thristian Richards and Blaise Bellville. According to Richards, the inspiration came to from the suggestion of British DJs BokBok and Oneman to use the web-streaming platform Ustream to enable internet users to virtually attend "bedroom"-style DJ-mixes filmed specifically for the web. On the "About" page of the project's website, "the UK's rich pirate radio heritage" is also mentioned as an influence. ${ }^{5}$ After having experimented with filming the recording of a DJ-mix originally intended for a mix-CD bundled with the magazine Platform, Richards and Bellville decided to invite DJs to show up at the offices of the magazine, accompanied by a small group of invited friends, to have their performances broadcast using web streaming technologies such as those offered by the platform Livestream. In 2012, specialist media outlets profiling this project noted the originality of this doubly entertaining event, highlighting the intimacy of an on-site, face-to-face event remediated online on a global scale. ${ }^{6}$ Two years later, Boiler Room gradually increased the frequency of their broadcasts, their filming locations, and the range of musical styles on offer, eventually offering multiple broadcasts per day on different continents.

The development of this activity is based on a particular business model, that of brand sponsorship. In exchange for their financial support, brands can have their logo displayed on various media associated with Boiler Room events. The organization also delegates production and recording expenses to record labels hoping to promote their artists through media exposure as well as the legitimacy associated with this media outlet. These economic dynamics force Boiler Room to judge between artistic choices catering to an audience depicted as specialist and demanding, and those brought about by financial dependence on record labels. 
An analysis of three webpages will permit us to observe the production of meaning surrounding a Boiler Room event dating from the project's initial period of development. I describe the manner in which a media configuration both invokes and inscribes itself within a cultural history of discothèques and DJ-mixes:

A page entitled "Boiler Room Berlin 006 / Dixon, Move D, Midnight Operator (Live) \& Jus-Ed". It is an event listing, comprised of a visual element that serves as a flyer, an unsigned text, and a series of musical excerpts.

A page entitled "LIVE", which is the live [web-TV] broadcast page. ${ }^{8}$ It is composed of a frame within which a video stream is broadcast using the viewing platform Livestream, along with a synchronous discussion forum ["chat room"].

A page entitled "Dixon's 30 min mix", which serves as an archive of the four performances originally broadcast on the evening of 25 January 2012. It provides access to video of Dixon's performance stored in the video-archiving platform Vimeo. Of particular interest here are the visual components featured in the video, which correspond to elements from the original "LIVE" broadcast page.

These pages were first observed in May of 2012, and the site has since undergone an overhaul that modified certain elements, but a proportion of the editorial choices remain the same. DJ Dixon's performance was chosen for analysis after several weeks of observing the website's activities. One of the reasons for this choice has to do with this episode's apparent success during broadcast-more so than any other episode during the same period-with web traffic managing to crash the video stream for several minutes at a time. Moreover, the disused pool "Stattbad Wedding" is a regular venue for Boiler Room events, and certain remarkable staging effects correspond to recurrent choices made by the organization during that phase of their development. For these reasons, this episode serves not as a marginal performance among those hosted by Boiler Room, but rather as a representative case that brings into relief a number of filmic directives. This corpus is occasionally complemented by observations drawn from the website's "About" page, the organization and appearance of the site as a whole during the time of study, and the mobilization of smaller media forms issuing from platforms such as Facebook and Twitter. The interpretation of these forms is based on an initial phase of general observation of platforms devoted to the broadcast of concerts online, in particular the "Concerts To Go" [Concerts à emporter] of websites La Blogothèque, ARTE Live Web, and Deezer Sessions. This process enables the identification of the particularities of Boiler Room's online and videographic rhetoric. This is followed by a mapping between these signs and references drawn from a corpus of ten primarily Anglophone academic works concerned with the history of DJs, mixing, and discothèques. These are summarized and more specialized works based on ethnographic and historical approaches, which I mobilize here as secondary sources of the imaginary of club culture and the DJ-mix. 
In order to represent the DJ-mix online, the organisers of Boiler Room employ different symbolic frameworks: the events during which the DJ plays in front of an audience, with associated knowledge and aesthetics; the use of videographic techniques, and contemporary internet practices. My approach consists of simultaneously analyzing (without conflating) the relations between the production of a musical experience valued by club culture and certain significations attributed to the pragmatic and media-specific aspects of its "mediations" (Hennion 2015). I will thus study the discourse found on the Boiler Room website, their techno-semiotic composition, the scenography of the event, and its videographic rhetoric, with the aim of revealing the symbolic challenges of media writing [écriture] that a dual onsite/online event poses. ${ }^{10} \mathrm{~W}$ ith the phrase "media writing" I signal the consideration of the poetics of "on-screen writing" - writing on/through the screen-along with its inscription in a particular editorial practice. ${ }^{11}$ The corpus of webpages chosen for analysis permits a view of editorial attempts to mediate between a logic of broad accessibility to all web users and a logic of tailored experience specific to a community of specialists. This entails understanding how a mediatizing project based on club culture constructs continuity between representations of community and online audio-visual production.

Through the choice of DJ, venue, and the manner of expressing these choices on the website, the organization builds an image of the reader as an informed amateur and then casts itself as a participant in the "authenticity" of a specialist culture; in keeping with the norms of musical appreciation of a DJ-mix produced on-site, seeking out kinesthetic and aesthetic effects, the staging of the performance flaunts the usual routines of concert videos (darkness, placement of the audience, static shot) in order to better offer the viewer a scopic position as witness to a small-scale cultural scene. Finally, the design of the website contributes to building a form of online event around broadcast, along with the image of communal success.

\section{InSCRIBING THE AUthenticity of the Local Event OnLINE}

Club and rave cultures have often carried with them a series of topical oppositions, which pits a mainstream, associated with commerce, spectacle, and conformism, against an "underground" stream characterized by disinterest, obscurity, and authenticity. Sarah Thornton, in her seminal monograph, sets out to take account of how actors promote this antinomy, identifying a "youthful commonsense that club culture is the inverse of broadcasting's domestic accessibility and that it is the antithesis of widely-disseminated tabloid talk" (Thornton 2013: 109). From the perspective of partygoers, "the general accessibility of broadcasting, in the strict sense of the word, is at odds with the esotericism and exclusivity of club and rave cultures; it too widely distributes the raw material of youth's subcultural capitals" (Thornton 2013: 124). This opposition between festive events and their mediatization is reinforced by negative associations made by the media with regards to nighttime and clubbing, and also by the technical challenges of transmitting festive energies across media. Similarly, Thornton notes that, between 1988 and 1992, the British television 
show The Hitman \& Her showed British viewers long sequences featuring a crowd dancing to popular music hits. She remarks that "the act of putting bright lights on the crowd as opposed to dance acts-the process of illuminating a culture that is supposed to take place in the dark-usually destroys the atmosphere that is the linchpin of club authenticity" (Thornton 2013: 127). Here, the event is optimized for television viewers to the detriment of its atmosphere in situ; and yet, this atmosphere is implicitly designated as the index of a club event's success and authenticity.

Boiler Room stages these musical and festive practices, and presents itself as taking part in the authenticity of a specialized culture. The notion of authenticity only appears explicitly on their website's "About" page, through the use of terms such as "sincere", "honest", and "authentic". ${ }^{12}$ This rhetoric contrasts clearly with the rest of the site, which conveys a more conspiratorial tone. On the event-listing page, written in a more colloquial and relaxed style, the repeated use of the first-person singular "I" and phrases such as, "I know we say stuff like that all the time", presumes a reader that is familiar and intimate. The description of the performing DJs is relatively elliptical, presuming that the reader trusts the curator's judgment: "Even if I say so myself"; "I'll guarantee that". Web users are even supposed to be acquainted with certain artists: "if you ever caught the guy in a club situation".

The flyer image posted on the event-listing page evokes the event in two ways: the heading "Boiler Room Berlin 006" and a set of geographic coordinates. The use of numeric geographic coordinates evokes encryption and playfully refers back to the esotericism of the flyers announcing the first rave parties in the United Kingdom, before the Criminal Justice Act (1994) outlawed this type of event. ${ }^{13}$ In a similar fashion, the background image of the flyer, framed by the pipes of the Stattbad Wedding swimming pool, represents the space while also referencing rave promoters' practice of using disused industrial sites as party venues. This space is also described by the page's authors as "our home", thus evoking intimacy and familiarity, which also underlines its inscription within a series revealed by the event's name: "Boiler Room Berlin 006". Viewed from the historical perspective of festive practices, this manner of presenting the event appears to be a compromise between the models of the rave and the club, which are two models of partying that include DJs, the former envisaging massive accessibility and the latter something more limited in scope, neither of which can claim a monopoly on "underground" values, since this concept is defined in opposition to both discrimination and the "masses" (Thornton 2013: 167). Since rave parties are forced to change location regularly in order to escape police intervention, rave locations can be imbued with an aura of novelty, whereas the club is more thoroughly ritualized. Through the codes of its flyer, Boiler Room thus draws from a double heritage to inscribe a Berliner swimming pool into the logic of club culture. Viewed from a perspective internal to this culture, one can apprehend the authenticity of this inscription as arising from choices-the right location, the right DJ-that appear to conform to cultural codes; but on the website these choices are doubled with a presentational rhetoric that completes this authenticity effect. By mobilizing images of objects familiar to its audience (such as the flyer), by employing a conspiratorial tone in its writing, and by organizing the 
website around searches by DJ names, Boiler Room has designed a specialist website that is nonetheless accessible to everyone.

\section{SCENOGRAPHY AND VIDEOGRAPHY OF THE DJ-MIX}

The website's evocation of intimacy through connotative play may seem a fragile ploy in itself. If readers are willing to identify with the conspiratorial tone of the event listing, they do so by suspending their awareness of the website's public accessibility. They enter into a double game corresponding to a certain form of specialized media that articulates between the wide accessibility of the internet and a specific mode of address on the surface of the page. And yet, in principle, the deployment of video on the "Live" and "Recordings" pages complicate the promise of proximity apparent on the event-listing page. As a musical medium, video is historically an expensive tool; when used in the context of intensive marketing campaigns, it represents a priori intentions for massive broadcasting and employs a rhetoric of spectacle, which aims to imitate or intensify musical effects. Boiler Room, however, is an exceptional case. Rather than making the DJ-mix more telegenic, they present the DJ as a participant in a cultural scene that the video merely captures.

DJ performances pose two problems for visual staging. The first has to do with technology: the DJ's instruments are two turntables and a mixing board ("mixer"). The turntables enable the playback of records that are mostly unknown to the audience. The mixer serves to shape, adjust, mix, and filter sonic frequencies. Most of the records were also created using the same filters and effects that are found on mixers. And so, it is difficult to identify from the sound alone which sonic transformations are the result of the DJ's actions and which are simply part of the recordings. Furthermore, in order to select records and adjust their speed, DJs must listen to a stream of sound through their headphones that differs from what is being broadcast. DJs must conceal this discontinuity by dancing and regularly demonstrating that they are "in sync" with the audience, that they share simultaneous enjoyment. It is these particularities of performance practice that often lead to oppositions between conventional "live" musicians and DJs. In contrast with the jazz concert as "ideal type", fans of DJ-mixes cannot assume that what they hear corresponds to the DJ "playing", in the musical sense. In contrast with the rock concert as ideal type, the DJs are not the sole charismatic source of the music, perhaps "playing" on that charisma to intensify musical effect. DJs only represent the music explicitly by indicating its source: the records; if they have a personal aura, they derive it from their role as mediator-technician.

The second problem facing the televised representation of DJ performance is the importance of duration:

Think of a DJing performance in a compressed time-frame. Where a guitarist can impress an audience by playing a thirty-second sequence of chords, what a DJ does takes a lot longer-a DJ needs to be judged on a two- or three-hour narrative of tracks (Brewster and Broughton 2006: 22). 
This opposition between the immediate effects of conventional music concerts and the gradual work of the DJ appears in the words of Jimmy Saville, the first DJ to have brought together a crowd to dance to sound recordings:

I didn't think I was an entertainer. What I was doing was creating an atmosphere. An entertainer sings, dances, tells jokes, juggles. I didn't do any of that (quoted in Brewster and Broughton 2006: 53).

This is not to say that a DJ performance cannot also be spectacular: the counterexamples are numerous. What is of importance here is that the aesthetic significations of the DJmix are often presented as invisible and requiring a particular mode of listening. For these various reasons, the staging of this performance as a concert or music video risks appearing "inauthentic". Boiler Room thus adjusts their double-mediation-the spatial arrangement of the event and their use of technology - and chooses to use static shot and live broadcast. The use of live broadcast as a form of shared time, an experience of simultaneity between the moment of recording and the moment of viewing, is an acquired form of media knowledge. On the internet, this is renewed by the mobilization of conventional signs. The presenceeffect generated by stressing this "live" aspect is reinforced by the naturalizing effect of the static shot. According to Fredric Jameson's reflections on experimental video, the static shot produces a sense of "pure temporality" and shared timing between the spectator and the body on the screen, which operates as a reality-effect on the temporal mode, as opposed to the montage of different shots, which invents a fictional temporality (Jameson 2007: 129-33).

The double choice of live streaming and static shots serves to compensate for the artifice of the scenography. Indeed, according to the usual staging practices of clubs and raves in the 2000s, web users wishing to find an "authentic scene" would more likely expect the DJ to face the dancers, rather than facing away from them as it happens here. The DJ faces the camera, which constitutes a sort of on-site relay for the eye of internet spectators, but without being visible themselves: this creates a degree of fluidity concerning the DJ-mix's intended audience. Since DJs are expected to adapt to their audience, they need to observe the crowd and adjust their mix to their reactions. Facing the camera, however, DJs can neither see the reactions of internet spectators nor observe those of the dancers behind them-short of turning around. It is thus through this unusual scenographic choice that Boiler Room not only mediatizes a musical performance, but connects it to a cultural scene. It is as if the group that appears on screen had been invited to produce for the camera a visible performance of a cross-section of a community of fans united around shared experience. This type of staging that binds together an aesthetic object with the staging of its reception in the same mediaform is not at all innovative: it refers, for example, back to the staged audiences of television variety shows. Rather, the originality of Boiler Room's programming is to be found in the compromise between the minimalism of video techniques, approaching the aesthetic of a webcam, and the decision to foreground the audience, which belongs more to professional television than club culture. 
The peculiar placement of the audience lends a somewhat contrived aspect to the local on-site event, but it also permits investing the DJ-mix with significations of community, presenting the video's soundtrack as an experience shared by a chosen few. The use of static shots, the weak lighting by televisual standards, and finally the incidental gestures of the DJ all have the advantage of adding nuance to the strangeness of the crowd's placement and its simulacrum-effect. Indeed, watching the video of Dixon spinning records mostly involves watching him turning a dial, listening to the sound for a few dozen seconds while shuffling about, taking a mouthful from his drink, glancing furtively at the camera, adjusting the next record, fixing his hair mechanically, smiling to someone nearby, listening and shuffling again, adjusting the knobs on the mixer, turning around to see the audience: the DJ's performance is visible only as a succession of more or less incidental gestures, as if the camera's presence was of no concern.

Thus, while the local event made reference to rave and club imaginaries through the choice of venue and its mode of online presentation, the minimalism of the video itself does not invite internet spectators to transform themselves into remote partygoers but rather places them in a position of eyewitnesses to a cultural scene of community.

\section{Figuring Communal Success and the Online Event}

While not going so far as to adopt the constant streaming of conventional television channels, Boiler Room sets a specific time for the broadcast of its sessions and thus offers video outside of an archival system, running more as a network. The organization thus hews close to the historical origins of radiophonic broadcast, the word "episode" [emission] originally describing the intermittent aspect of broadcast programs. Web users are invited to pause for a moment in their net-surfing to virtually attend an episode. This interruptive aspect of the media event, which led Dayan and Katz (1994) to coin "festive television", finds parallels in club culture, especially in the intermittent character of British pirate radio broadcasts, but also in the "record hops" of the disco era, recounted as "small parties and underground events" that "engendered garage sessions and illegal raves" and represented "a forum for new musical directions and DJ arts, from disco to hip-hop" (Poschardt 2002: 111). One finds some mention of these events in literature or television series: for example, in Tom Wolfe's essay, “The Noonday Underground”, he describes a young English worker letting off steam at lunchtime discotheques in 1968: two hundred and fifty people at Tiles, "underground at noon-a vast black room heaving with music and human bodies" (quoted in Poschardt 2002: 132). In the twenty-fifth episode of its fifth season, the American television series The Office referred to the same type of space-time: a "disco café" built on the floor below the employees' offices threatens their productivity when they go dancing during their breaks.

If the symbolic value attached to DJs and to the space-time they seem to enchant with their presence may seem sufficient reason to make web streaming a moment not to be missed, Dayan and Katz have shown that "television ceremonies" tend to occur in association with a cluster of peripheral programs in order to better guide the spectator towards an experience 
of the mediatized happening as media-event. The particularity of numerous contemporary platforms for online writing such as Facebook and Twitter can be found in the injunction addressed to web users to produce micro-texts and to put into circulation media productions using semi-automatized modes of writing. Before, during, and after the broadcast, these branded web-tools are mobilized to signal the "live" broadcast as a moment to experience and recount. "Timeline" framing elements drawn from these platforms appear on the "Live" page immediately underneath the live video stream. Fixed thusly to the broadcasting framework, these objects take advantage of the connotations of social affinity organized on Facebook and Twitter to suggest that the DJ-mix resembles a community of experience online. Web users who possess "profiles" registered with these platforms thus find themselves invited by Boiler Room to redouble the broadcast's status as event through the spectacle of the status update. The timeline on the page serves as an exemplar: giving prominence to such micro-publishing enjoin users to write in turn. The same result is encouraged by a series of micro-signs that attempt to make online expression a low-cost technological operation-"in one click"-according to "an economic logic of least effort" (Candel and Gomez-Mejia 2013). In this way, the activation of the intermediary sign "Tweet" triggers the opening of a web-browser window with a pre-written message of the form "LIVE @boileroom http:// [link]", which the user can simply edit and publish. With regards to Facebook, the injunction to quick, colloquial writing is explicit-"discuss this event" - and reinforced by the antechronological dating of comments: “[\#\#] minutes ago".

This production of real-time interest in the broadcast is accompanied by a highlighting of its popularity. Like other internet-based industries, Boiler Room "capitalizes on-screen the systematic production of values related to activity, current events, gregariousness, and popularity" (Gomez-Mejia 2011: 395). The "Like" and "Tweet" buttons are juxtaposed with small bubbles representing the sum of comments published mentioning that page on each of these social media sites. Re-textualizations of an icon such as the "Like" button can take on different meanings: "personal expression, indication of a potential audience for a brand, or reader endorsement" (Candel and Gomez-Mejia 2013: 145). The manner in which it is positioned in the "Live" page suggests that, from the point of view of the page's designers, the ambiguity between these three sorts of statements does not pose a challenge to the imagination of a limited and specialized community. The number " 83,000 " on this page, which remains visible even when the broadcast is not taking place, means that the button is not exclusively linked to the broadcast itself, but also to the page as a whole. The consubstantial ambiguity of this micro-form, which brings a variety of intentionalities to the same polling symbol, and whose ultimate meaning remains unresolved in the absence of a legend, is thus instrumentalized by Boiler Room to imply mass popularity. This valorization of popularity "by the numbers" may seem to be contradictory to the image of a specialized community, unless one considers Facebook's imaginary of identity and affinity- "profiles"; "friends"; etc. - which is concentrated in the micro-form "Like + [\#\#\#". This icon can thus circulate in various spaces, and the number can reach impressive heights, all the while carrying positive connotations. 
There is thus, all other things being equal, a logical affinity between two approaches to dual entertainment, those of Facebook and Boiler Room. Boiler Room creates an event that is accessible [in person] to a limited group, in order to then give everyone access to it via broadcast, all the while suggesting through its discourse that internet spectators are not there by accident. Facebook incites users to create a network of "friends" to whom their micro-publications are primarily addressed, all the while making them available to everyone else-according to the platform's default privacy settings - in the moment as well as afterwards, as an archive. The use of the "Like" button by Boiler Room thus takes on the traits of a fruitful encounter-symbolically as well as commercially-between the imagery of underground music and those of social media websites. Media exposure, a source of criticism within these worlds, is doubly neutralized here. It is firstly neutralized by its proximity to all of the signs on the "Live" and "Recordings" pages-limited audience in the video, web layout - that mobilize specialized knowledge and, secondly, by the interpretation of the number associated with the word "Like", as if referring to the number of potential "friends" included in a group of user-publishers whose co-presence on the same social media site might indicate possible affinities. This media-based establishment of a paradoxical community success would thus constitute the sort of compromise both dreamed of and sought after by stakeholders, between the values of underground musical experience on the one hand and the principle of media-accessibility on the other-and all rendered possible through a strategic use of contemporary online mediation.

\section{NOTES}

1 Original publication: Guillaume Heuguet. 2015. "Quand la culture de la discothèque est mise en ligne". Culture et Musées 24: 107-24. < musees-collections-expositions/revue-culture-et-musees-n-24>

2 [Translator: The original term used in French is "le mix", to refer to the predominant mode of musical performance in electronic dance music cultures. As an English loanword, its usage in French does not risk being confused with other, more common meanings of the term in English. In English, a more common equivalent term would be the "DJ set", but this loses the metaphorical reference to mixing, which is at times important for the author's semiotic reading. Instead, I have simply translated the term as "DJ-mix", which is also a valid (albeit less idiomatic) term in English.]

3 [Translator: Although Saville was not the first to play records in a dance hall, he claims to have been the first disc jockey to use twin turntables to ensure a constant stream of music to accompany dancing.]

4 See: http://boilerroom.tv/about/ (Accessed 1 May 2012). This page, as it was observed in May of 2012, has a particular status because it seems to be addressed primarily to potential commercial partners while nonetheless remaining readable by any web user. The layout of the text itself evokes a commercial presentation with prominent and concise subject headings, the name BOILER ROOM set in bold capital letters, and a general tonality of promise 
that resembles a press release. Notably, this text concludes with a comment that addresses expectations regarding relations with sponsoring brands: "By working solely with brands we respect we are building a truly sustainable model".

[Translator: for an archived version of the page on 4 May 2012, see: https://web.archive.org/ web/20120504190932/http://boilerroom.tv/about/]

5 According to Simon Reynolds, "abandoning the last vestiges of mainstream pop-radio protocol", the British pirate radios that accompanied the rave movement "sounded like 'raves on the air: rowdy, chaotic...with a strong emphasis on audience participation (enabled by the spread of the portable cellular phone)" (Reynolds 1998: 265).

6 See: http://www.c-heads.com/2012/04/19/interview-with-the-co-founder-of-boilerroombpm/ (Accessed 8 September 2014).

7 See: http://boilerroom.tv/session/boiler-room-berlin-006-dixon-move-d-midnight-operatorlive-jus-ed/ (Accessed 1 May 2012).

8 See: http://boilerroom.tv/live/ (Accessed 1 May 2012).

9 See: http://boilerroom.tv/dixons-30-min-mix-2 (Accessed 1 May 2012).

10 This approach in terms of "media writing" [écriture médiatique] and "on-screen writing" [écrit d'écran] is indebted to the work of Souchier on editorial enunciation as well as Souchier and Jeanneret on the poetics of on-screen writing (Souchier 1998; Souchier and Jeanneret 1999).

11 "From the socio-semiotic perspective on digital media, the notion of on-screen writing [écrit d'écran] does not dissociate the surface of writing produced on the screen from the structuring of the text made possible by the technological apparatus" (Souchier and Jeanneret 2009). This concept is especially useful here for thinking through the media productions set up by a similar enunciative instance, that is, "web pages" that integrate multiple regimes of writing: text, images, video, and combinations of programming code associated with small-scale visual forms like the "Like" button, which are connected to a cultural memory of media.

12 See: http://boilerroom.tv/about/ (Accessed 1 May 2012).

[Translator: for an archived version of the page on 4 May 2012, see: https://web.archive.org/ web/20120504190932/http://boilerroom.tv/about/]

13 Traditionally, instead of designating a site, rave flyers would provide a telephone number ("hotline"). Calling the hotline would result in increasingly specific information on the venue's location. This strategy helped to prevent the police from discovering the rave's location too early and preventing the event from happening. Thanks to this system, when police officers finally arrived to the scene, the thousands of attendees made it difficult for police to operate effectively.

\section{REFERENCES}

Becker, Howard. 1985. Outsiders: Etudes de sociologie de la déviance. Paris: Editions Métaillé.

Blanchard Gérard. 1987. "Les videoclips". Communication et langages 72(1): 49-57. < $\underline{\text { http:// }}$ dx.doi.org/10.3406/colan.1987.972>

Bouquillion, Philippe, Bernard Miège and Pierre Mœglin. 2013. L'industrialisation des biens symboliques: les industries créatives en regard des industries culturelles. Grenoble: Presses universitaires de Grenoble. 
Bouquillon, Philippe. 1992. "Le spectacle vivant, de l'économie administrée à la marchandisation". Sciences de la societé 26: 95-105.

Brewster, Bill and Frank Broughton. 2007. Last Night a DJ Saved My Life. New York: Grove Press.

Candel, Etienne. 2013. "Penser le web comme 'social': sur les lectures contemporaines des écrits de réseau". In Réseaux socionumériques et médiations humaines: Le social est-il soluble dans le web?, ed. Estrella Rojas, 33-60. Paris: Lavoisier.

Candel, Etienne, Valérie Jeanne-Perrier and Emmanuel Souchier. 2012. "Petites formes, grands desseins : d'une grammaires des énoncés éditoriaux à la standardisation des écritures”. In L'économie des écritures sur le web vol 1. Les traces d'usage dans un corpus de sites de tourisme, ed. Jean Davallon, 165-202. Paris: Hermès.

Candel, Etienne and Gustavo Gomez-Mejia. 2013. "Le bouton 'Like' ou les ressorts d'un clic". In Manuel d'analyse du web en sciences humaines et sociales, ed. Christine Barats, 141-46. Paris: Armand Colin.

Dayan, Daniel and Elihu Katz. 1994. Media Events: The Live Broadcasting of History. Boston: Harvard.

Fikentscher, Kai. 2000. "You Better Work!”: Underground Dance Music in New York City. Hanover: Wesleyan University Press.

Glevarec, Hervé, and Michel Pinet. 2009. "La 'tablature' des goûts musicaux : un modèle de structuration des préférences et des jugements”. Revue française de sociologie 50(3): 599-640. <http://dx.doi.org/10.3917/rfs.503.0599>

Gomez-Mejia, Gustavo. 2011. "De l'industrie culturelle aux fabriques de soi ? Enjeux identitaires des productions culturelles sur le Web contemporain”. Ph.D. Dissertation, (Sciences de l'Information et de la Communication), CELSA (Centre d'études littéraires et scientifiques appliquées).

Hennion, Antoine. 2007. La passion musicale: une sociologie de la médiation. Paris: Editions Métailié.

- - - 2015. The Passion for Music: A Sociology of Mediation. London: Ashgate.

Jameson, Fredric. 2007. La postmodernité ou la logique culturelle du capitalisme tardif. Paris: Beaux-Arts de Paris.

Jeanneret, Yves. 2014. Critique de la trivialité. Les médiations de la communication, enjeu de pouvoir. Paris: Editions Non Standard.

Jouvenet, Morgan. 2001. “Emportés par le mix: Les DJ et le travail de l'émotion”. Terrain 37. <http://dx.doi.org/10.4000/terrain.1297>

Lawrence, Tim. 2003. Love Save's the Day. A History of American Dance Music Culture, 1970-1979. Durham: Duke University Press.

Le Guern, Philippe. 2012. "Un spectre hante le rock... L'obsession patrimoniale, les musiques populaires et actuelles et les enjeux de la 'muséomomification'". Questions de communication 22:7-44. <http://dx.doi.org/10.4000/questionsdecommunication.6820>

Maisonneuve, Sophie. 2009. L'invention du disque 1877-1949: genèse de l'usage des médias musicaux contemporains. Paris: Archives contemporaines.

Poschardt, Ulf. 2002. DJ Culture. Paris: Kargo. 
Reynolds, Simon. 1998. Energy Flash: A Journey Through Rave Music and Dance Culture. London: Picador.

Shapiro, Peter. 2007. Turn the Beat Around: The Secret History of Disco. London: Faber \& Faber. Thornton, Sarah. 2013. Club Culture: Music, Media and Subcultural Capital. Hoboken: Wiley. 